\title{
Evaluation of Effect of Diameter of Saphenous Vein on Stump Length after Radiofrequency Ablation for Varicose Vein
}

\author{
Ayman Essawy ${ }^{(1)}$, Hussein Kamal ${ }^{(2)}$, Taha Bahgat Abdelsalam ${ }^{(3)}$, Ahmed \\ Abdeltawab Abdelhamed Mohammed ${ }^{(4)}$ \\ ${ }^{(1)}$ Professor of General \& Vascular Surgery, Faculty of Medicine, Fayoum \\ University \\ (2) Professor of General \& Vascular Surgery, Faculty of Medicine, Cairo \\ University \\ ${ }^{(3)}$ Lecturer of General Surgery, Faculty of Medicine, Alazhar University \\ ${ }^{(4)}$ M.B.B.Ch. Faculty of Medicine, Cairo University
}

\begin{abstract}
Background: There have been tremendous changes to the treatment of varicose veins over the years. High ligation of the SFJ and stripping of the GSV have been considered as standard treatments for GSV insufficiency for more than one century and it is still adopted as the preferred method in the majority of the surgical centers. However, the increase in minimally invasive treatments such as EVLA, radiofrequency ablation (RFA), ultrasound-guided foam sclerotherapy and cryostripping have given excellent results. Most patients undergoing these minimal invasive treatments were satisfied with their results.
\end{abstract}

Objective: To evaluate the effect of diameter of great saphenous vein on stump length after radiofrequency ablation for varicose veins.

Methods: In this study we have followed 30 cases underwent RFA and we can say that the results were quite satisfying. After the RF ablation, no major complications occurred (recurrence, recanalization) at the time of the study, minor complications however, were quite common and included bruising /ecchymosis, postoperative pain that required analgesics, superficial thrombophlebitis that was very responsive to medical treatment.

Results: Radiofrequency ablation of varicose veins with recently used ClosureFastTM (Covidien, Mansfield, MA, USA) catheter showed that there is no correlation between preoperative diameter of GSV and postoperative length of its stump. Therefore, RFA is continuing to be an outstanding minimal invasive method for treatment of varicose veins with minimal complications and a very short recovery period disregarding the vein diameter which sounds appealing to the patients. 
Conclusion: The diameter of the saphenous vein has no correlation with the length of stump after RFA. As long as ClosureFastTM (Covidien, Mansfield, MA, USA) catheter was used for ablation with its tip placed $2 \mathrm{~cm}$ distal to $\mathrm{SFJ}$, under locally injected Tumescent anaethesia.

Keywords: Saphenous Vein; Varicose Vein; Radiofrequency Ablation

\section{INTRODUCTION}

Varicose veins are a common vascular disease. The reported incidence of varicose vein ranges from $1 \%$ to $73 \%$ for females and $2 \%$ to $56 \%$ in males. It is part of chronic venous disease, which is reported to have a substantial negative impact on healthrelated quality of life. Before the worldwide spread of endovenous therapy, high ligation and stripping of the saphenous vein has been the standard treatment for patients with varicose vein (Lohr and Kulwicki, 2010).

Since late 1990s, endovenous treatment of varicose veins such as radiofrequency ablation (RFA) and endovenous laser ablation (EVLA) became available. Recent randomized controlled trials revealed that endovenous treatment showed better results than traditional high ligation and stripping in terms of reduced pain, better quality of life, faster recovery, and lower rate of recurrence (Carradice et al., 2011; Rasmussen et al., 2011).

Although RFA and EVLA showed similar truncal vein occlusion, RFA was associated with less periprocedural pain, analgesic requirement, and bruising (Nordon et al., 2011).

The ClosureFastTM (Covidien, Mansfield, MA, USA) catheter, which is used to perform RFA, treats a 7-cm vein segment in a 20 -second energy cycle. The vein wall is heated conductively by a $7-\mathrm{cm}$ coil at the distal end of the catheter. The diameter of the saphenous vein should be considered before RFA since a venous diameter $>12 \mathrm{~mm}$ has been considered controversial when RFA was performed with the previously used ClosurePlusTM (VNUS Medical Technologies, San Jose, CA, USA) catheter. However, the $12-\mathrm{mm}$ size limitation was no longer issue in studies with the ClosureFastTM (Covidien, Mansfield, MA, USA) catheter. In the study from the ClosureFastTM (Covidien, Mansfield, MA, USA) Europe Group, exclusion criteria did not consider the venous diameter. The evaluation of occlusion status of the saphenous vein and the stump length of the remaining saphenofemoral or saphenopopliteal junction dependent on saphenous vein diameter may give us a clue for the proper indications of RFA in terms of the saphenous venous diameter.

Until now, however, there have been few data about the correlation between the diameter of the saphenous vein and the stump length after RFA. The purpose of our study was to investigate its correlation.

\section{AIM OF THE WORK}

To evaluate the effect of diameter of great saphenous vein on stump length after radiofrequency ablation for varicose veins. 


\section{PATIENTS AND METHODS}

\section{Study design}

This prospective study includes 30 patients undergoing Radiofrequency ablation for treatment of primary great saphenous varicose veins in Fayoum University Hospitals and Arab Contractors Medical Center with approved ethical committee consents. All patients received information about surgical technique and risks of the procedure and written consent was taken from all patients.

The thirty patients were recruited in the study according to the following inclusion criteria: unilateral or bilateral great saphenous varicose veins who are fit for the procedure with age range (18-60 years).

Exclusion Criteria of the study were: History of acute deep venous thrombosis, primary deep venous reflux, superficial thrombophlebitis, duplex proven deep venous abnormalities e.g. congenital stenosis, and bed ridden patients.

\section{Procedure}

\section{Preoperative patients was evaluated} by:

○ Full History taking, History includes Co-morbidities e.g DM, HTN, IHD, Coagulopathies, Hyperlipidemia, old CVS.

○ Radiological assessment of diameter of great saphenous vein, incompetent saphenofemoral junction \& deep venous system patency and competency using Duplex scan.
○ All patients received information about surgical technique and risks of the operation.

○ Giving instructions to patients about the importance of early ampulation and elastic compression after procedure.

\section{Radiofrequency ablation:}

All the patients underwent Radiofrequency ablation in operation room under optimum temperature $24^{\circ} \mathrm{C}$ under local anesthesia.

\section{Operative details}

○ Patient preparation, disinfection and drapping

- Intra operative duplex assessment of diameter of great saphenous vein and saphenofemoral junction.

○ Duplex guided tumescent injection $100-300 \mathrm{~mL}$ of a $555-\mathrm{mL}$ solution composed of $(500 \mathrm{~mL}$ of $0.9 \mathrm{~N}$ saline $+50 \mathrm{~mL}$ of $1 \%$ lidocaine with 1:100,000 epinephrine $+5 \mathrm{~mL}$ of $8.4 \%$ sodium bicarbonate) along course of great saphenous vein.

- Cannulation of GSV using 21gauge needle and a $7 \mathrm{fr}$ sheath at mid leg.

O Insertion of ClosureFastTM (Covidien, Mansfield, MA, USA) catheter with tip placed $2 \mathrm{~cm}$ distal to sapheno-femoral junction.

- Segmental RFA of GSV starting $2 \mathrm{~cm}$ distal to SFJ at intervals of 7 $\mathrm{cm}$ heating the vein to $120^{\circ} \mathrm{C}$ during each 20 -second cycle. The first segment was treated twice.

○ At the end of the procedure leg is drapped in elastic bandage and patient is encouraged for early ambulation. 


\section{Postoperative patients care:}

○ Postoperative elastic compression was applied to all patients immediately after the procedure for 2 weeks.

O All patients were encouraged early ambulation immediately after surgery.

O All patients were discharged on the same day on anti-inflammatory drugs and pain killers.

○ Documentation of early postoperative major complications eg bleeding or severe pain.

○ All patients were followed up postoperatively for any complaints eg, LL pain, swelling or sudden attack of dyspnea.

O All patients had done Duplex venous scan at 2 weeks, 3 months and 6 months post operation for assessment of GSV stump length.

○ Evaluation of preoperative GSV diameter in relation to postoperative stump length at 2 weeks, 3 months and 6 months intervals.

\section{Statistical Analysis}

Data were collected, revised, coded and entered to the Statistical Package for Social Science (IBM SPSS) version 23. The quantitative data were presented as mean, standard deviations and ranges when their distribution found parametric. Also qualitative variables were presented as number and percentages. While comparison between more than two paired groups with quantitative data and parametric distribution were done by using repeated measure ANOVA test. Spearman correlation coefficients were used to assess the correlation between two quantitative parameters in the same group. The confidence interval was set to $95 \%$ and the margin of error accepted was set to $5 \%$.

\section{RESULTS}

The mean age of the cohort was $34.63 \pm 6.70$ years (range $21-45$ ). 16 out of 30 patients were females $(53.3 \%)$ and 14 out of 30 patients were males $(46.7 \%)$. The mean weight of the cohort was $85.93 \pm 8.81 \mathrm{kgs}$ (range $62-105$ ). The mean BMI of the cohort was $29.53 \pm 3.07$ (range $24-37$ ). 21 out of 30 patients had unilateral varicosities $(70.0 \%)$ and 9 out of 30 patients had bilateral varicosities (30\%) with a total of 39 limbs.

Table (1): Descriptive data regarding Demographic data

\begin{tabular}{|c|c|c|}
\hline \multicolumn{2}{|c|}{} & No. $=\mathbf{3 0}$ \\
\hline \multirow{2}{*}{ Age } & Mean \pm SD & $34.63 \pm 6.70$ \\
& Range & $21-45$ \\
\hline \multirow{2}{*}{ Sex } & Female & $16(53.3 \%)$ \\
& Male & $14(46.7 \%)$ \\
\hline \multirow{2}{*}{ Weight } & Mean \pm SD & $85.93 \pm 8.81$ \\
& Range & $62-105$ \\
\hline BMI & Mean \pm SD & $29.53 \pm 3.07$ \\
\hline
\end{tabular}




\begin{tabular}{|c|c|c|}
\hline & Range & $24-37$ \\
\hline \multirow{2}{*}{ Laterality } & Unilateral & $21(70.0 \%)$ \\
& Bilateral & $9(30.0 \%)$ \\
\hline
\end{tabular}

The mean diameter of GSV of the cohort was $9.64 \pm 2.17$ Range $(6-14)$.

Table (2): Descriptive data regarding Diameter of GSV and Stump in ( 2 weeks, 3 months, and 6 months)

\begin{tabular}{|c|c|c|}
\hline \multicolumn{2}{|c|}{} & No. $=\mathbf{3 9}$ \\
\hline \multirow{2}{*}{ Diameter of GSV in mm } & Mean \pm SD & $9.64 \pm 2.17$ \\
& Range & $6-14$ \\
\hline \multirow{2}{*}{ Stump length 2 wks in mm } & Mean \pm SD & $10.00 \pm 0.86$ \\
& Range & $9-12$ \\
\hline \multirow{2}{*}{ Stump length 3 mnts in mm } & Mean $\pm S D$ & $10.03 \pm 0.93$ \\
& Range & $9-12$ \\
\hline \multirow{2}{*}{ Stump length 6 mnts in mm } & Mean \pm SD & $10.03 \pm 0.93$ \\
& Range & $9-12$ \\
\hline
\end{tabular}

Postoperative GSV stump length in 2 weeks was $10.00 \pm 0.86$ with range (912), 3 months was $10.03 \pm 0.93$ with range $(9-12)$ and 6 months was $10.03 \pm 0.93$ with range $(9-12)$.

Table (3): Descriptive data regarding Post operative complications

\begin{tabular}{|c|c|c|c|}
\hline \multicolumn{2}{|c|}{ Post operative Complications } & No. & \% \\
\hline \multirow{2}{*}{ Parenthesis } & No & 37 & $94.9 \%$ \\
& Yes & 2 & $5.1 \%$ \\
\hline \multirow{2}{*}{ Ecchymosis } & No & 36 & $92.3 \%$ \\
& Yes & 3 & $7.7 \%$ \\
\hline \multirow{2}{*}{ DVT } & No & 39 & $100.0 \%$ \\
& Yes & 0 & $0.0 \%$ \\
\hline \multirow{2}{*}{ Phlebitis } & No & 36 & $92.3 \%$ \\
& Yes & 3 & $7.7 \%$ \\
\hline \multirow{2}{*}{ Recurrence } & No & 39 & $100.0 \%$ \\
& Yes & 0 & $0.0 \%$ \\
\hline
\end{tabular}

Postoperative complications:

- 2 patients out of 30 had parathesia that improved onPregabalin-lyrica- $75 \mathrm{mg}$ once daily and vitamin B complex.

- 3 patients out of 30 had ecchymosis that improved spontaneously.

- 3 patients out of 30 had phlebitis that improved on elastic stockings and topical (recombinant hirudin) and systemic anti-inflammatory (chymotrypsin + trypsin).

- No patient had DVT or recurrence over the follow up period. 
Table (4): Correlation between Diameter of GSV and Stump length in (2weeks, 3 months, and 6 months)

\begin{tabular}{|c|c|c|}
\hline \multirow{2}{*}{} & \multicolumn{2}{|c|}{ Diameter of GSV in mm } \\
\cline { 2 - 3 } & r & P-value \\
\hline \multicolumn{3}{|c|}{ Stump length } \\
\hline 2 weeks & 0.170 & 0.301 \\
\hline 3 months & 0.209 & 0.202 \\
\hline 6 months & 0.209 & 0.202 \\
\hline
\end{tabular}

The previous table shows that there was no relation between Diameters of GSV and Stumps length.

Table (5): Comparison of Stump length in (2weeks, 3months, and 6 months)

\begin{tabular}{|c|c|c|c|c|c|c|}
\hline Stump length & $\mathbf{2}$ weeks & 3 months & 6 months & \multirow{2}{*}{ Test value• P-value } & Sig. \\
\cline { 2 - 7 }$(\mathbf{m m})$ & No. $=\mathbf{3 0}$ & No. $=\mathbf{3 0}$ & No. $=\mathbf{3 0}$ & & \\
\hline $\begin{array}{c}\text { Mean } \pm \text { SD } \\
\text { Range }\end{array}$ & $\begin{array}{c}10.00 \pm 0.86 \\
9-12\end{array}$ & $\begin{array}{c}10.03 \pm 0.93 \\
9-12\end{array}$ & $\begin{array}{c}10.03 \pm 0.93 \\
9-12\end{array}$ & 0.140 & 0.711 & NS \\
\hline
\end{tabular}

P-value >0.05: Non significant (NS); P-value <0.05: Significant (S); P-value< 0.01: highly significant (HS)

\section{•: Repeated measure ANOVA test}

The Previous table shows that there was no statistically significant difference between (2weeks, 3months, and 6 months) regarding Stump length.

\section{DISCUSSION}

Varicose veins are a common vascular disease. The reported incidence of varicose vein ranges from $1 \%$ to $73 \%$ for females and $2 \%$ to $56 \%$ in males. It is part of chronic venous disease, which is reported to have a substantial negative impact on health-related quality of life. Before the worldwide spread of endovenous therapy, high ligation and stripping of the saphenous vein has been the standard treatment for patients with varicose vein (Van Schil et al., 2009).

Since late 1990s, endovenous treatment of varicose veins such as radiofrequency ablation (RFA) and endovenous laser ablation (EVLA) became available. Recent randomized controlled trials revealed that endovenous treatment showed better results than traditional high ligation and stripping in terms of reduced pain, better quality of life, faster recovery, and lower rate of recurrence. Although RFA and EVLA showed similar truncal vein occlusion, RFA was associated with less periprocedural pain, analgesic requirement, and bruising (Chwala et al., 2015).

In 2006, the ClosureFastTM (Covidien, Mansfield, MA, USA) catheter was introduced. This catheter allowed for segmental ablation instead of a continuous pull-back needed for the previous ClosurePlusTM (VNUS Medical Technologies, San Jose, CA, USA). The manufacturer recommends that the catheter tip should be positioned $2 \mathrm{~cm}$ distal to the SFJ. This procedure also entails two 20-second treatment cycles in the segment closest to the SFJ using external compression with the ultrasound probe. The complete occlusion of the proximal saphenous segment allows for hemodynamically effective control of truncal reflux (Proebstle and Van den Bos, 2017). 
This study was carried on 30 patients with age range (21-45 years), 16 females and 14 males, with BMI range (24-36). 9 out of 30 patients had bilateral varicose veins with total number of 39 limbs. All the patients were treated using Radiofrequency ablation in operation room under optimum temperature $24^{\circ} \mathrm{C}$ under local anesthesia. All patient were discharged on the same day (with one day hospital stay) and encouraged for early ambulation, elastic compression was applied to all patients immediately after the procedure for 2 weeks.

In our study, the mean preoperative diameter of GSV was $9.67 \pm 2.31 \mathrm{~mm}$ with range $(6-$ $14 \mathrm{~mm})$, postoperative follow up using duplex scan was done in 2 weeks, 3 months and 6 months intervals to assess GSV stump length. Postoperative GSV stump length in 2 weeks was $10.13 \pm 0.90 \mathrm{~mm}$ with range $(9-12 \mathrm{~mm}), 3$ months was $10.20 \pm 0.96 \mathrm{~mm}$ with range $(9-$ $12 \mathrm{~mm})$ and 6 months was $10.20 \pm 0.96 \mathrm{~mm}$ with range $(9-12 \mathrm{~mm})$. Moreover, we analyzed the relationship between the two factors. On correlation analysis, the Pearson correlation coefficient was -0.423 which means that there is no correlation between the saphenous diameter and stump length.

\section{Postoperative complications:}

2 patients out of 30 had parathesia that improved on lyrica $75 \mathrm{mg}$ once daily and vitamin B complex.

3 patients out of 30 had ecchymosis that improved spontaneously.

3 patients out of 30 had phlebitis that improved on elastic stockings and topical (recombinant hirudin) and systemic anti-inflammatory (chymotrypsin + trypsin).

No patient had DVT or recurrence over the follow up period.

The diameter of the saphenous vein was previously one of the criteria for RFA. The original device for RFA was a catheter which had extendable prongs which would make contact with the saphenous vein wall. In the fully deployed state, the larger of the 2 available devices was $12 \mathrm{~mm}$ in diameter. Thus, it was originally thought that the maximum diameter of a treated vein should be $12 \mathrm{~mm}$. The newer RFA device, ClosureFastTM (Covidien, Mansfield, MA, USA) catheter, no longer had extendable prongs making a maximum catheter contact diameter. In the study reported by Proebstle et al., saphenous veins as large as $18 \mathrm{~mm}$ in diameter were treated with the ClosureFastTM (Covidien, Mansfield, MA, USA) catheter. There was an overall closure rate of $99.6 \%$ in their study. According to the study by GarcíaMadrid et al., the maximal venous diameter for RFA was $19 \mathrm{~mm}$. The immediate occlusion rate was $100 \%$.

However, there was no report about the relationship between saphenous vein diameter and stump length. As puplished by GarcíaMadrid in Ann Vasc Surg on 2013 reported that stump length was $13.9 \pm 7.7 \mathrm{~mm}$ (range, 0 $30 \mathrm{~mm}$ ). However, they did not reveal the relationship between the saphenous vein diameter and the stump length. In that study, the mean preoperative diameter was $6.7-6.8$ $\mathrm{mm}$.

There are several possible explanations about these results. Firstly, tumescent solution, injected around the saphenous vein, compresses the vein against the catheter, thus ensuring contact of larger veins. Manfrini et al as puplished inVasc Surg on $\mathbf{2 0 0 0}$ reported the use of tumescent anesthesia during RFA. For obtaining this effect as well as anesthesia, most of trials used tumescent injection for RFA procedures. Secondly, the deliver $y$ temperature for treatment is constant. The treatment temperature is $120 \mathrm{oC} \quad(248 \mathrm{oF})$ created by the proximal coiling $7 \mathrm{~cm}$ segment of the catheter. If treatment were to be performed by continuous pull-back, the treatment temperature could change. Thirdly, ablation at the proximal segment was started 2 
cm distal from the SFJ or SPJ in all patients. According to the clinical practice guidelines of the Society for Vascular Surgery and the American Venous Forum, the tip of the catheter should be positioned $1 \mathrm{~cm}$ distal to the confluence with the superficial epigastric vein or $2 \mathrm{~cm}$ distal to the SFJ (Manfrini et al., 2000).

Certain studies on the saphenous vein stump after endovenous treatment suggest that its presence may contribute to the formation of late inguinal varicose vein recurrence. Geier et al. reported that a long residual saphenofemoral stump was present in approximately two-thirds of patients with symptomatic groin recurrences. Therefore, the stump length should be kept as short as possible. Several factors may affect the stump length after RFA, including the initial position of the delivery catheter tip, as well as the saphenous vein diameter. The saphenous vein diameter may be the major factor affecting the stump length. In the present study, a positive correlation between saphenous vein diameter and stump length was identified immediately after the procedure. No correlation was identified between the saphenous vein diameter and stump length immediately after the procedure and on post-operative day 14 . The initial position of the catheter tip was $2 \mathrm{~cm}$ distal to the junction in all patients (Geier et al., 2008).

A similar study was done in department of Surgery, Kyung Hee University Medical Center, Seoul, Korea. During the study period, 277 consecutive patients (346 limbs) underwent operation for varicose vein. The mean age was $52.4 \pm 11.9$ years with a range of 19 to 84 years. The female to male ratio was 164:113. RFA was performed in 201 patients. The conventional high ligation and stripping was done in patients whose saphenous veins were shallow (less than $10 \mathrm{~mm}$ from the skin) or had a junctional aneurysm of more than 20 $\mathrm{mm}$. This procedure was performed in 70 patients. If the cause of varicose vein was a reflux of perforator veins only, ligation of the perforator at the level of the muscular fascia and stab phlebectomy was done (5 patients). EVLA was also done in one patient (Jusung Kim et al., 2015).

RFA was performed in 201 patients with primary varicose veins. RFA was done simultaneously if the GSV and SSV in the same leg showed refluxes of $\geq 0.5$ second. In one session, one truncal vein was ablated in 132 patients, 2 truncal veins in 64 patients, and 3 truncal veins in 3 patients. Four truncal veins were ablated simultaneously in 2 patients. After RFA, there were several types of complications. The most common complication was paresthesia, which occurred in 18 patients $(9.0 \%)$, followed by ecchymosis in 12 patients $(6.0 \%)$, cord-like mass in 9 patients $(4.5 \%)$, hyperpigmentation in 8 patients $(4.0 \%)$, erythema over the ablated saphenous vein in 3 patients (1.5\%), EHIT detected by postoperative duplex scanning in 3 patients $(1.5 \%)$. Postoperative duplex scanning revealed class II EHIT in 2 patients and class III EHIT in one patient. All EHIT's resolved without anticoagulation (Jusung Kim et al., 2015).

After 2 years (mean follow-up, 13.9 \pm 6.9 months), the stump lengths from the SFJ or SPJ to the leading point of occlusion were obtained in 74 limbs (52 patients), 56 limbs with GSV ablation and 18 limbs with SSV ablation. The mean length was $12.5 \pm 8.5 \mathrm{~mm}$. The preoperative duplex scans revealed that the mean diameter of the saphenous vein was $6.7 \pm 1.8 \mathrm{~mm}$ (7.7-11.2 $\mathrm{mm})$. The Pearson correlation coefficient for correlation analysis was -0.017 . There was no correlation between the saphenous vein diameter and stump length (Jusung Kim et al., 2015). 


\section{CONCLUSION}

The diameter of the saphenous vein has no correlation with the length of stump after RFA. As long as ClosureFastTM (Covidien, Mansfield, MA, USA) catheter was used for ablation with its tip placed $2 \mathrm{~cm}$ distal to $\mathrm{SFJ}$, under locally injected Tumescent anaethesia.

\section{REFERENCES}

Carradice D, Mekako AI, Mazari FA, Samuel N, Hatfield J, Chetter IC. Clinical and technical outcomes from a randomized clinical trial of endovenous laser ablation compared with conventional surgery for great saphenous varicose veins. Br J Surg. 2011; 98:1117-1123.

Chwała M, Szczeklik W, Szczeklik M, Aleksiejew-Kleszczyński T, JagielskaChwala M. Varicose veins of lower extremities, hemodynamics and treatment methods. Advances in clinical and experimental medicine: official organ Wroclaw Medical University. 2015;24(1):5-14.

García-Madrid C, Pastor Manrique JO, Sánchez VA, Sala-Planell E. Endovenous radiofrequency ablation (vene-fit procedure): impact of different energy rates on great saphenous vein shrinkage. Ann Vasc Surg. 2013;27:314-321.

Geier B, Stucker M, Hummel T, Burger P, Frings N, Hartmann $M$, Stenger $D$, Schwahn-Schreiber C, Schonath $M$ and Mumme A. Residual stumps associated with inguinal varicose vein recurrences: A multicenter study. Eur J Vasc Endovasc Surg 2008; 36: 207-210.

Jusung Kim F, Sungsin C, Jin HJ, HyungJoon A, and Ho-Chul P. Vascular Specialist International 2015; 31(4).

Lohr J, Kulwicki A. Radiofrequency ablation: evolution of a treatment. Semin Vasc Surg. 2010;23:90-100.
Manfrini S, Gasbarro V, Danielsson G, Norgren L, Chandler JG, Lennox AF et al. Endovenous management of saphenous vein reflux. Endovenous Reflux Management Study Group. J Vasc Surg.2000;32:330-342.

Nordon IM, Hinchliffe RJ, Brar R, Moxey P, Black SA, Thompson MM et al. A prospective double-blind randomized controlled trial of radiofrequency versus laser treatment of the great saphenous vein in patients with varicose veins. Ann Surg. 2011;254:876-881.

Proebstle T and Van den Bos R. Endovenous ablation of refluxing saphenous and perforating veins. Vasa 2017; 46 (3), 159-166.

Rasmussen LH, Lawaetz M, Bjoern L, Vennits B, Blemings A, Eklof B. Randomized clinical trial comparing endovenous laser ablation, radiofrequency ablation, foam sclerotherapy and surgical stripping for great saphenous varicose veins. $\mathrm{Br} \quad \mathrm{J}$ Surg. 2011;98:1079-1087.

Van Schil PE, Philipsen TE, De Maeseneer MG, Vandenbroeck CP. Anatomical patterns of the above knee great saphenous vein and its tributaries: implications for endovenous treatment strategy'. Acta Chir Belg 2009; 109:176-9. 